\title{
MOS-C Based Electronically Tuneable Current/Voltage-Mode Third Order Quadrature Oscillator and Biquadratic Filter Realization
}

\author{
Hasan Cicekli ${ }^{1 \text {, * }}$, Ahmet Gokcen ${ }^{2}$ \\ ${ }^{I}$ Department of Informatics, Hatay Mustafa Kemal University, \\ Antakya, Hatay, Turkey \\ ${ }^{2}$ Faculty of Engineering and Natural Sciences, Iskenderun Technical University, \\ Iskenderun, Hatay, Turkey \\ cicekli@mku.edu.tr
}

\begin{abstract}
This paper introduces a new electronically tuneable third order quadrature oscillator and biquadratic filter with MOS-C realization using all grounded passive components. Voltage-mode second order low-pass, high-pass, band-pass filters using second generation current conveyor and a current/voltage-mode third order quadrature sinusoidal oscillator using multi-output second generation current conveyor are synthesized from the proposed circuit topology. All synthesized circuits are compatible with integration and the center frequency can be electronically tuned by the gate voltage of the MOS transistors. The proposed circuits do not need any component matching condition. Oscillation condition and frequency of oscillation can be independently controlled. Workability of the proposed circuits is validated by PSPICE software using 0.18 micrometer MOSIS CMOS process parameters at $\pm 0.9 \mathrm{~V}$ supply voltage. Tuneability of the oscillator is demonstrated for a tested frequency range both in voltage-mode and current-mode operations.
\end{abstract}

Index Terms-Biquadratic filter; MOS-C; Quadrature sinusoidal oscillator; Third order.

\section{INTRODUCTION}

Quadrature sinusoidal oscillators produce two sinusoid signals with $90^{\circ}$ phase difference in periodic form, and they are commonly used in signal processing applications, telecommunication, measurement, instrumentation, and industrial control systems. They play an essential role in phase modulators, quadrature mixers, and single-sideband generators [1], [2]. Since the sinusoidal signals have gained substantial importance in electronics engineering, numerous quadrature sinusoidal oscillator implementations employing various novel active building blocks, such as operational trans-conductance amplifier (OTA) [3], current feedback operational amplifier (CFOA) [4], [5], various types of current conveyor [6]-[14], current differencing buffered amplifier (CDBA) [15]-[18], current differencing transconductance amplifier (CDTA) [19]-[21], four terminal floating nullor (FTFN) [22], operational trans-resistance amplifier (OTRA) [23], modified current differencing unit (MCDU) [24], differential-input buffered and trans-

Manuscript received 10 October, 2020; accepted 11 March, 2021. conductance amplifier (DBTA) [25], dual-output controlled gain current follower buffered amplifier (DO-CG-CFBA) [26], have been reported in the recent years. However, there is one or more drawbacks of these reported circuits, such as the usage of floating capacitor, which is inconvenient for integrated circuit (IC) technology, lack of electronic tuneability, and non-existence of both voltage-mode and current-mode outputs in the same topology.

It is a fact that high order circuits exhibit better frequency response, work more accurately, and achieve better distortion performance than the lower order circuits [27]. Therefore, the realization of third order oscillator has received considerable attention in recent years [28]-[44]. Design of a quadrature sinusoidal oscillator using passive components, which are all grounded, has always been popular due to its suitability for integration techniques and due to it occupies less chip space. Furthermore, a topology which provide both current-mode and voltage-mode outputs is a desired factor for dual-mode operations. The objective of this article is to introduce a new current/voltage-mode MOS-C third order quadrature oscillator employing multioutput second generation current conveyors (MOCCII) and all grounded passive components. Main features of the proposed oscillator are given below:

1. Use of CMOS based active resistors, which makes the circuit compatible with monolithic integration;

2. Oscillation condition and frequency of oscillation can be controlled independently and electronically;

3. Availability of both voltage-mode and current-mode quadrature outputs in the same topology;

4. Capacitors are all grounded, which is a desired feature for integration [45] and beneficial in parasitic capacitance absorption [46];

5. Suitability for low voltage applications.

Table I shows a comparison of various realizations of third order sinusoidal oscillator circuits to demonstrate the highlights of the proposed topology. The comparison table suggests these considerations:

1. One or more floating components are used in [28], [29], [31]-[35], [37], [38], [40], [41], and [44];

2. Quadrature outputs are not available in [29] and [38]; 
3. Different type active elements in the same topology are used in [35], [36], and [43];

4. Topologies in [29], [31], [33], [34], [36]-[38], [41], [43], and [44] do not have MOS-C realization, which is a need for integration;

5. Electronic tuneability is not available in [29], [31], [33], [34], [37], [38], [41], and [43];
6. Both current-mode and voltage-mode outputs are not available in the same topology in [28], [29], [32], [34][38], [40], and [44];

7. Frequency tuning can be done using symmetrical voltage in [40], which is not practical as much as using a single control voltage like in the proposed circuit.

TABLE I. COMPARISON OF VARIOUS THIRD ORDER SINUSOIDAL OSCILLATOR CIRCUITS.

\begin{tabular}{|c|c|c|c|c|c|c|c|c|}
\hline $\begin{array}{l}\text { Circuit } \\
\text { Referen } \\
\text { ce }\end{array}$ & $\begin{array}{l}\text { Active Element/ } \\
\text { Implementation } \\
\text { Technology }\end{array}$ & $\begin{array}{l}\text { Supply } \\
\text { Voltage }\end{array}$ & $\begin{array}{c}\text { Passive Component } \\
\text { No./Connection Type } \\
\text { (R: Resistor, C: } \\
\text { Capacitor) } \\
\end{array}$ & $\begin{array}{c}\text { MOS-C } \\
\text { Structure }\end{array}$ & $\begin{array}{c}\text { Availability } \\
\text { of } \\
\text { Quadrature } \\
\text { Outputs } \\
\end{array}$ & $\begin{array}{l}\text { Operation } \\
\text { Mode }\end{array}$ & $\begin{array}{l}\text { Measured } \\
\text { Frequency/ } \\
\text { THD }\end{array}$ & $\begin{array}{l}\text { Quadrature } \\
\text { Phase Error }\end{array}$ \\
\hline [28] & $\begin{array}{c}3 \times \text { OTRA/ } \\
\text { CMOS } 0.5 \mu \mathrm{m}\end{array}$ & $\pm 1.5 \mathrm{~V}$ & $\begin{array}{l}\text { R: 5/all floating, } \\
\text { C: } 3 \text { /all floating }\end{array}$ & Yes & Yes & VM & $\begin{array}{c}159 \mathrm{kHz} \\
0.57 \%\end{array}$ & N/A \\
\hline [29] & $\begin{array}{c}1 \times \text { OTRA/ } \\
\text { CMOS } 0.35 \mu \mathrm{m}\end{array}$ & $\pm 2.5 \mathrm{~V}$ & $\begin{array}{c}\text { R: 3/all floating, } \\
\text { C: } 3 / \text { two grounded, one } \\
\text { floating }\end{array}$ & No & No & VM & $\begin{array}{c}99.1 \mathrm{kHz} \\
1.9 \%\end{array}$ & - \\
\hline$[30]$ & $\begin{array}{c}3 \times \text { CDTA/ } \\
\text { CMOS } 0.18 \mu \mathrm{m}\end{array}$ & $\pm 1.25 \mathrm{~V}$ & C: 3/all grounded & Yes & Yes & VM/CM & $\begin{array}{c}<1 \mathrm{MHz} \\
\mathrm{V}_{\mathrm{O} 1}: 10.39 \% \\
\mathrm{~V}_{\mathrm{O} 2}: 9.19 \% \\
\end{array}$ & N/A \\
\hline [31] & $\begin{array}{c}2 \times \text { MOCCII/ } \\
\text { CMOS } 0.18 \mu \mathrm{m}\end{array}$ & $\pm 1.25 \mathrm{~V}$ & $\begin{array}{c}\text { R: 3/two grounded, one } \\
\text { floating, } \\
\text { C: } 3 / \text { all grounded }\end{array}$ & No & Yes & VM/CM & $\begin{array}{c}<1 \mathrm{MHz} \\
\mathrm{V}_{\mathrm{O} 1}: 2.39 \% \\
\mathrm{~V}_{\mathrm{O} 2}: 2.95 \%\end{array}$ & N/A \\
\hline$[33]$ & $\begin{array}{c}3 \times \mathrm{DVCC} / \\
\mathrm{CMOS} 0.5 \mu \mathrm{m}\end{array}$ & $\pm 2.5 \mathrm{~V}$ & $\begin{array}{c}\text { R: 3/two grounded, one } \\
\text { floating, } \\
\text { C: 3/all grounded }\end{array}$ & No & Yes & VM/CM & $\begin{array}{c}7.94 \mathrm{MHz} \\
\mathrm{V}_{\mathrm{O} 1}: 1.34 \% \\
\mathrm{~V}_{\mathrm{O} 2}: 0.84 \%\end{array}$ & N/A \\
\hline$[34]$ & $\begin{array}{c}2 \times \text { OTRA/ } \\
\text { CMOS } 0.5 \mu \mathrm{m}\end{array}$ & $\pm 1.5 \mathrm{~V}$ & $\begin{array}{l}\text { R: 3/all floating, } \\
\text { C: 3/all floating }\end{array}$ & No & Yes & VM & $\begin{array}{c}29.04 \mathrm{kHz} / \\
1.17 \% \\
5.10 \mathrm{kHz} / \\
1.32 \% \\
\end{array}$ & N/A \\
\hline$[35]$ & $\begin{array}{c}1 \times \text { CA, } \\
1 \times \text { VDTA/ } \\
\text { Commercial IC }\end{array}$ & $\pm 5 \mathrm{~V}$ & $\begin{array}{c}\text { R: 1/floating, } \\
\text { C: } 3 / \text { two grounded, one } \\
\text { floating }\end{array}$ & - & Yes & VM & $\begin{array}{c}10.28 \mathrm{MHz} \\
<1 \%\end{array}$ & N/A \\
\hline [36] & $\begin{array}{c}1 \times \text { DDCC, } \\
2 \times \text { OTA/ } \\
\text { CMOS } 0.25 \mu \mathrm{m}\end{array}$ & $\pm 1.25 \mathrm{~V}$ & $\begin{array}{c}\text { R: 1/grounded, } \\
\text { C: 3/all grounded }\end{array}$ & No & Yes & VM & $\begin{array}{c}1.69 \mathrm{MHz} \\
1.75 \%\end{array}$ & N/A \\
\hline [37] & $\begin{array}{c}2 \times \text { ICFOA/ } \\
\text { CMOS } 0.35 \mu \mathrm{m}\end{array}$ & N/A & $\begin{array}{c}\text { R: } 3 / \text { all floating, } \\
\text { C: } 3 / \text { two grounded, one } \\
\text { floating }\end{array}$ & No & Yes & VM & $\begin{array}{l}1.35 \mathrm{MHz} \\
\text { N/A }\end{array}$ & N/A \\
\hline$[38]$ & $\begin{array}{c}1 \times \text { OTRA/ } \\
\text { CMOS } 0.18 \mu \mathrm{m}\end{array}$ & $\pm 0.9 \mathrm{~V}$ & $\begin{array}{c}\text { R: 3/all floating, } \\
\text { C: } 3 / \text { one grounded, two } \\
\text { floating }\end{array}$ & No & No & VM & $\begin{array}{c}8.82 \mathrm{MHz} \\
<2.6 \%\end{array}$ & - \\
\hline [39] & $\begin{array}{c}2 \times \text { VDTA/ } \\
\text { CMOS } 0.18 \mu \mathrm{m}\end{array}$ & $\pm 0.9 \mathrm{~V}$ & C: 3/all grounded & Yes & Yes & VM/CM & $\begin{array}{c}3.18 \mathrm{MHz} \\
<4.5 \%\end{array}$ & $<3 \%$ \\
\hline$[40]$ & $\begin{array}{c}2 \times \text { FDCCII/ } \\
\text { CMOS } 0.18 \mu \mathrm{m}\end{array}$ & $\pm 1.25 \mathrm{~V}$ & $\begin{array}{l}\text { R:4 / all floating, } \\
\text { C: } 3 / \text { one grounded, two } \\
\text { floating }\end{array}$ & Yes & Yes & VM & $\begin{array}{c}1.56 \mathrm{MHz} \\
<3 \%\end{array}$ & N/A \\
\hline [41] & $\begin{array}{c}1 \times \text { FDCCII/ } \\
\text { CMOS } 0.35 \mu \mathrm{m}\end{array}$ & $\pm 1.65 \mathrm{~V}$ & $\begin{array}{c}\text { R: 3/two grounded, one } \\
\text { floating, } \\
\text { C: } 3 / \text { all grounded }\end{array}$ & No & Yes & $\mathrm{VM} / \mathrm{CM}$ & $\begin{array}{c}0.88 \mathrm{MHz} \\
\mathrm{V}_{\mathrm{O} 1}: 1.66 \% \\
\mathrm{~V}_{\mathrm{O} 2}: 0.70 \%\end{array}$ & N/A \\
\hline [42] & $\begin{array}{c}1 \times \text { MCCFTA/ } \\
\text { CMOS } 0.25 \mu \mathrm{m}\end{array}$ & $\pm 1 \mathrm{~V}$ & C: 3/all grounded & Yes & Yes & $\mathrm{VM} / \mathrm{CM}$ & $\begin{array}{c}2.7 \mathrm{MHz} \\
\mathrm{V}_{\mathrm{O} 1}: 0.26 \% \\
\mathrm{~V}_{\mathrm{O} 2}: 0.17 \%\end{array}$ & $<7 \%$ \\
\hline [43] & $\begin{array}{c}2 \times \mathrm{CCII}, \\
1 \times \mathrm{UVC} / \\
\text { CMOS } 0.18 \mu \mathrm{m}\end{array}$ & $\pm 1.2 \mathrm{~V}$ & $\begin{array}{l}\text { R: 3/all grounded, } \\
\text { C: 3/all grounded }\end{array}$ & No & Yes & VM/CM & $\begin{array}{c}1.43 \mathrm{MHz} \\
\mathrm{V}_{\mathrm{O} 1}: 0.19 \% \\
\mathrm{~V}_{\mathrm{O} 2}: 0.86 \%\end{array}$ & N/A \\
\hline [44] & $\begin{array}{c}3 \times \text { OTRA/ } \\
\text { CMOS } 0.25 \mu \mathrm{m}\end{array}$ & $\pm 2.5 \mathrm{~V}$ & $\begin{array}{l}\text { R: 5/all floating, } \\
\text { C: 3/all floating }\end{array}$ & No & Yes & VM & $\begin{array}{c}315 \mathrm{kHz} \\
\mathrm{V}_{\mathrm{O} 1}: 2.79 \% \\
\mathrm{~V}_{\mathrm{O} 2}: 4.82 \%\end{array}$ & N/A \\
\hline $\begin{array}{c}\text { Propose } \\
\mathrm{d}\end{array}$ & $\begin{array}{c}2 \times \text { MOCCII } \\
1 \times \text { CCII } / \\
\text { CMOS } 0.18 \mu \mathrm{m}\end{array}$ & $\pm 0.9 \mathrm{~V}$ & $\begin{array}{l}\text { R: 5/all grounded, } \\
\text { C: 3/all grounded }\end{array}$ & Yes & Yes & $\mathrm{VM} / \mathrm{CM}$ & $\begin{array}{c}3.24 \mathrm{MHz} \\
\mathrm{V}_{\mathrm{O} 1}: 2.00 \% \\
\mathrm{~V}_{\mathrm{O} 2}: 2.94 \%\end{array}$ & $<2.5 \%$ \\
\hline
\end{tabular}

Note: VM - Voltage-mode, CM - Current-mode, N/A - Not Available. 
The content of the remaining chapters of this paper is composed as follows. In Section II, the definition of the second generation current conveyor is given and the proposed topology is demonstrated. Circuit analysis is done and the synthesized filters are depicted also in this section. In Section III, the basic concept of third order oscillator is given. Proposed topology of third order oscillator is introduced and its MOS-C implementation is depicted in the second part of this section. Section IV contains the analysis of non-ideal effects. In Section V, the simulation results of both the proposed filter and quadrature oscillator circuits are given. Electronic tuneability of the oscillator is also demonstrated in this section. Section VI presents the outcome of the study.

\section{CIRCUIT DESCRIPTION}

\section{A. Basic Concept of Second Generation Current Conveyor}

Current conveyor is a versatile active circuit element. It has been used very beneficially in analogue signal processing since many current conveyor types give the researchers flexibility to design multipurpose circuits. Second generation current conveyor (CCII) is the most common type of current conveyor and it has three terminals which are represented by $x, y$, and $z$. Operation of the element can be briefly described as the input voltage of the $y$ terminal is conveyed to $x$ terminal and $x$ terminal current is conveyed to the $z$ output terminal. Multi-output CCII (MOCCII) can be easily obtained by connecting additional output stages to the CCII. The circuit schematic of MOCCII is shown in Fig. 1.

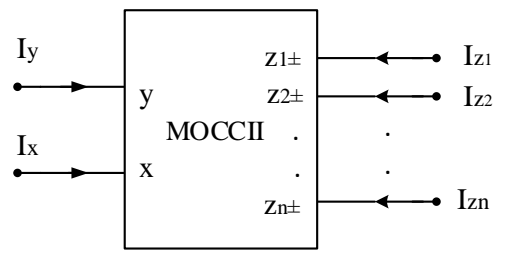

Fig. 1. Circuit schematic of multi-output CCII (MOCCII).

Definition equation of MOCCII can be given as

$$
\left[\begin{array}{l}
I_{y} \\
V_{x} \\
I_{z 1} \\
I_{z 2} \\
\cdot \\
\cdot \\
I_{z n}
\end{array}\right]=\left[\begin{array}{ccccccc}
0 & 0 & 0 & 0 & . & . & 0 \\
1 & 0 & 0 & 0 & . & . & 0 \\
0 & \pm 1 & 0 & 0 & . & . & 0 \\
0 & \pm 1 & 0 & 0 & . & . & 0 \\
\cdot & . & . & . & . & . & . \\
. & . & . & . & . & . & . \\
0 & \pm 1 & 0 & 0 & . & . & 0
\end{array}\right]\left[\begin{array}{c}
V_{y} \\
I_{x} \\
V_{z 1} \\
V_{z 2} \\
\cdot \\
. \\
V_{z n}
\end{array}\right] .
$$

In the third and following rows of the matrix, the positive sign indicates that $z$ terminal current $\left(I_{z}\right)$ flows in the same direction with $x$ terminal current $\left(I_{x}\right)$, whereas the negative sign indicates that $z$ terminal current flows in the opposite direction with $x$ terminal current. Terminal $y$ exhibits infinite input impedance, thus it is assumed that no current flows through the $y$ terminal. Terminal $z$ has very high impedance (ideally infinite).

\section{B. Proposed Circuit Topology}

The proposed biquadratic filter topology is illustrated in Fig. 2.

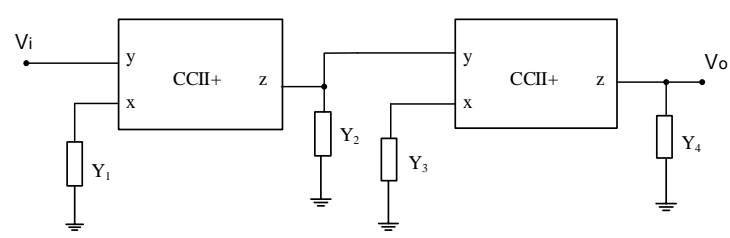

Fig. 2. Proposed filter topology.

Using the definition equation of CCII+ and carrying out the circuit analysis, the voltage transfer function is calculated as

$$
\frac{V_{o}}{V_{i}}=\frac{Y_{1} Y_{3}}{Y_{2} Y_{4}}
$$

As given in Table II, low-pass (LP), high-pass (HP), and band-pass (BP) filter circuits can be synthesized by different combinations of four admittances. Transfer functions and angular frequency equations are given in the same table.

TABLE II. ADMITTANCE SELECTION AND TRANSFER FUNCTIONS OF THE PROPOSED FILTER.

\begin{tabular}{|c|c|c|c|c|c|c|}
\hline Filter Type & $\mathbf{Y}_{\mathbf{1}}$ & $\mathbf{Y}_{\mathbf{2}}$ & $\mathbf{Y}_{\mathbf{3}}$ & $\mathbf{Y}_{\mathbf{4}}$ & Transfer Function & Angular Frequency \\
\hline $\mathrm{LP}$ & $G_{1}$ & $G_{2}+s C_{2}$ & $G_{3}$ & $G_{4}+s C_{4}$ & $\frac{G_{1} G_{3}}{s^{2} C_{2} C_{4}+s\left(C_{2} G_{4}+C_{4} G_{2}\right)+G_{2} G_{4}}$ & $\frac{1}{\sqrt{R_{2} R_{4} C_{2} C_{4}}}$ \\
\hline $\mathrm{HP}$ & $s C_{1}$ & $G_{2}+s C_{2}$ & $s C_{3}$ & $G_{4}+s C_{4}$ & $\frac{s^{2} C_{1} C_{3}}{s^{2} C_{2} C_{4}+s\left(C_{2} G_{4}+C_{4} G_{2}\right)+G_{2} G_{4}}$ & $\frac{1}{\sqrt{R_{2} R_{4} C_{2} C_{4}}}$ \\
\hline $\mathrm{BP}$ & $G_{1}$ & $G_{2}+s C_{2}$ & $s C_{3}$ & $G_{4}+s C_{4}$ & $\frac{s C_{3} G_{1}}{s^{2} C_{2} C_{4}+s\left(C_{2} G_{4}+C_{4} G_{2}\right)+G_{2} G_{4}}$ & $\frac{1}{\sqrt{R_{2} R_{4} C_{2} C_{4}}}$ \\
\hline
\end{tabular}

Figure 3 shows the MOS-C implementation of the synthesized filters.

Quality factor ( $Q$ ) of the filters is calculated as

$$
\mathrm{Q}=\frac{\sqrt{R_{2} R_{4} C_{2} C_{4}}}{R_{2} C_{2}+R_{4} C_{4}} .
$$

Sensitivity of passive components is calculated as:

$$
\begin{gathered}
S_{R_{2}}^{\omega_{0(L P)}}=S_{R_{4}}^{\omega_{0(L P)}}=S_{C_{2}}^{\omega_{0(L P)}}=S_{C_{4}}^{\omega_{0(L P)}}=-0.5, \\
S_{R_{1}}^{\omega_{(L P)}}=S_{R_{3}}^{\omega_{0(L P)}}=0, \\
S_{R_{2}}^{\omega_{(H P)}}=S_{R_{4}}^{\omega_{0(H P)}}=S_{C_{2}}^{\omega_{0(H P)}}=S_{C_{4}}^{\omega_{0(H P)}}=-0.5, \\
S_{C_{1}}^{\omega_{0(H P)}}=S_{C_{3}}^{\omega_{(H P)}}=0, \\
S_{R_{2}}^{\omega_{0(B P)}}=S_{R_{4}}^{\omega_{0(B P)}}=S_{C_{2}}^{\omega_{0(B P)}}=S_{C_{4}}^{\omega_{0(B P)}}=-0.5,
\end{gathered}
$$




$$
S_{R_{1}}^{\omega_{0(B P)}}=S_{C_{3}}^{\omega_{0(B P)}}=0
$$

It is evident from (4)-(9) that for all filter types, the angular frequency sensitivity to passive component variations is less than unity.

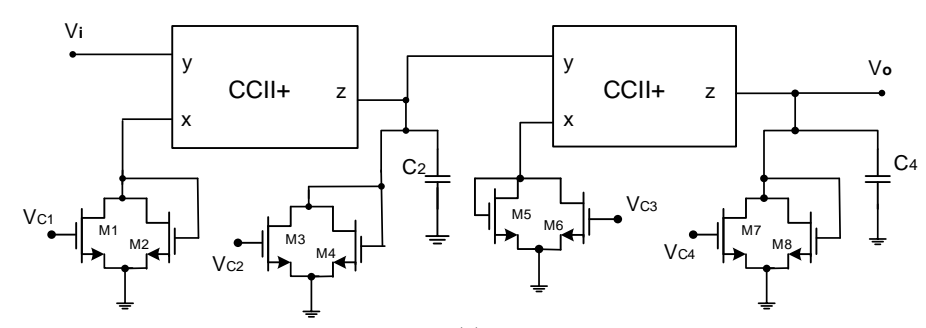

(a)

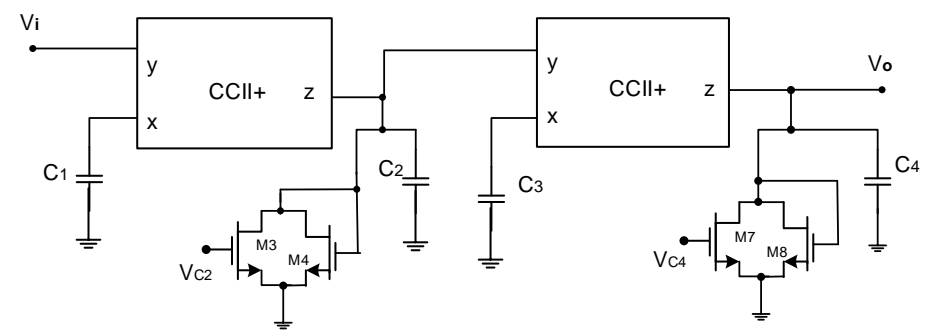

(b)

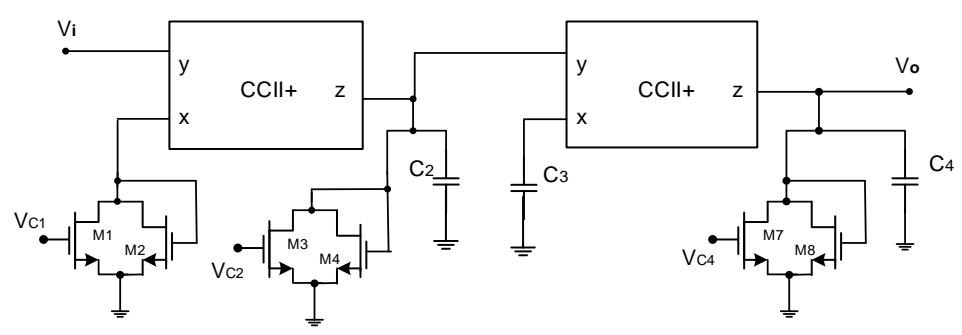

(c)

Fig. 3. MOS-C implementation of the synthesized filters: (a) LP filter; (b) HP filter; (c) BP filter.

\section{REALIZATION OF THIRD ORDER QUADRATURE OSCILLATOR}

\section{A. Basic Concept of Third Order Oscillator}

Figure 4 illustrates the schematic diagram of third order oscillator realization method used in this study. It consists of a second order low-pass filter and an inverting integrator, which is feedback connected to form a closed loop. The system's loop gain is $A(s) \times \beta(s)$ where $A(s)$ denotes the low-pass filter's transfer function and $\beta(s)$ denotes the gain of the inverting integrator.

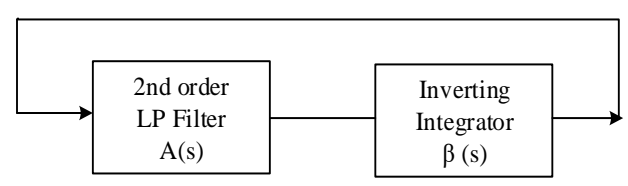

Fig. 4. Schematic diagram of third order quadrature oscillator.

The key of starting oscillation is ensuring that the circuit satisfies the criterion given by the following equation

$$
1-A(s) \beta(s)=0 .
$$

This condition is known as the Barkhausen criterion and it points out that the gain of the closed loop is equal to unity. When this criterion is satisfied, the circuit will provide quadrature sinusoidal signals at a single frequency.

\section{B. Proposed Third Order Oscillator Topology}

The proposed oscillator is realized by cascade connecting the low-pass filter, which is synthesized from the topology given in Fig. 2, and inverting the integrator circuit in a closed loop yields a unity gain. The obtained oscillator and MOS-C realization of the circuit are given in Fig. 5 and Fig. 6 , respectively.

By circuit analysis, the equation which satisfies the condition of oscillation can be found as

$$
\left[\frac{G_{1} G_{3}}{s^{2} C_{2} C_{4}+s\left(C_{2} G_{4}+C_{4} G_{2}\right)+G_{2} G_{4}}\right]\left[-\frac{1}{s C_{5} R_{5}}\right]=1 .
$$

Characteristic equation is obtained as

$$
s^{3}+s^{2} \frac{\left(C_{2} G_{4}+C_{4} G_{2}\right)}{C_{2} C_{4}}+s \frac{G_{2} G_{4}}{C_{2} C_{4}}+\frac{G_{1} G_{3} G_{5}}{C_{2} C_{4} C_{5}}=0 .
$$

Frequency of oscillation is calculated as

$$
\omega_{0}=\frac{1}{\sqrt{R_{2} R_{4} C_{2} C_{4}}}
$$

As seen from Fig. 6, the oscillation frequency can be electronically tuned by the gate voltage of MOSFETs. The oscillation condition is given by 


$$
G_{1} G_{3} G_{5} C_{2} C_{4}=G_{2} G_{4} C_{5}\left(C_{2} G_{4}+C_{4} G_{2}\right) .
$$

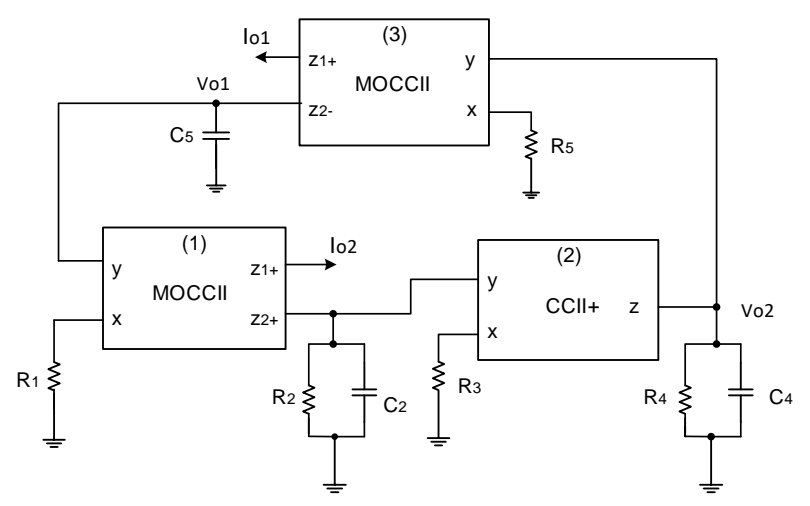

Fig. 5. Circuit schematic of the proposed quadrature oscillator.

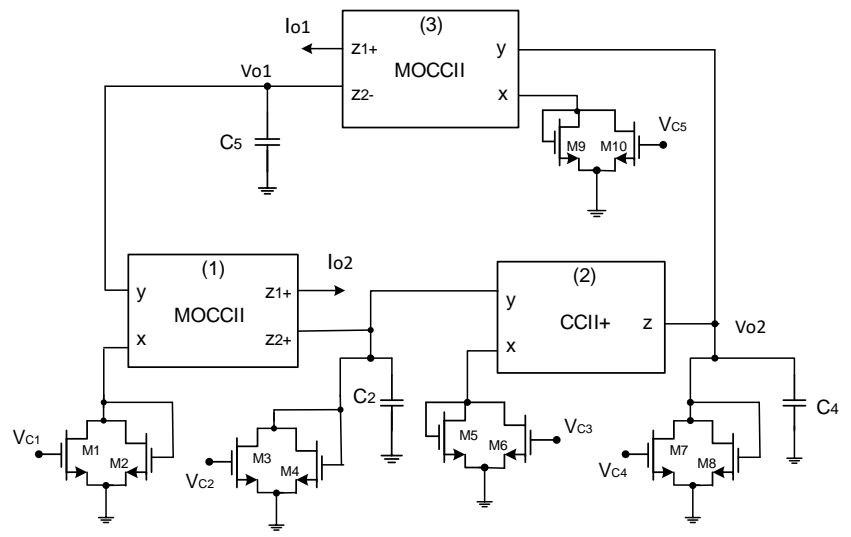

Fig. 6. MOS-C implementation of the proposed quadrature oscillator.

Considering (13) and (14), $R_{1}, R_{3}, R_{5}$, and $C_{5}$ can control the oscillation condition without interacting with the oscillation frequency. Likewise, the oscillation frequency can be tuned by $R_{2}, R_{4}, C_{2}$, and $C_{4}$.

Circuit analysis yields the current transfer function from $I_{o 2}$ to $I_{o 1}$ as

$$
\frac{I_{o 2}(s)}{I_{o 1}(s)}=\frac{1}{s R_{1} C_{5}}
$$

In the sinusoidal steady state, (15) can be rewritten as

$$
\frac{I_{o 2}(j \omega)}{I_{o 1}(j \omega)}=\frac{1}{\omega R_{1} C_{5}} e^{-j 90^{0}} .
$$

It is evident from (16) that the phase shift between $I_{o 1}$ and $I_{o 2}$ is $-90^{\circ}$. Thus $I_{o 1}$ and $I_{o 2}$ verified to be in quadrature.

Voltage transfer function from $V_{o 2}$ to $V_{o 1}$ is calculated as

$$
\frac{V_{o 2}(s)}{V_{o 1}(s)}=s R_{5} C_{5} .
$$

In the sinusoidal steady state, (17) can be rewritten as

$$
\frac{V_{o 2}(j \omega)}{V_{o 1}(j \omega)}=\omega R_{5} C_{5} e^{j 90^{0}}
$$

Equation (18) shows that the phase shift between $V_{o 1}$ and $V_{o 2}$ is $90^{\circ}$. Thus $V_{o 1}$ and $V_{o 2}$ verified to be in quadrature.

Frequency sensitivity to passive component variations is calculated as

$$
S_{R_{2}}^{\omega_{0}}=S_{R_{4}}^{\omega_{0}}=S_{C_{2}}^{\omega_{0}}=S_{C_{4}}^{\omega_{0}}=-0.5
$$

Equation (19) shows that the frequency sensitivity to all passive elements is lesser than unity.

\section{NON-IDEAL ANALYSIS}

In the ideal case, the current transfer ratio $(\alpha)$ between $x$ and $z$ terminals and the voltage transfer ratio $(\beta)$ between $x$ and $y$ terminals are both assumed to be equal to unity. However, in non-ideal case, by taking into consideration the current tracking error, which is denoted as $\varepsilon_{i}$, and the voltage tracking error, which is denoted as $\varepsilon_{v}$, parameters of the CCII, the current and voltage transfer ratios can be expressed as $\alpha=1-\varepsilon_{i}$ and $\beta=1-\varepsilon_{v}\left(\left|\varepsilon_{i}\right|<<1,\left|\varepsilon_{v}\right|<<1\right)$. In this context, the definition equation of the CCII can be expressed as follows

$$
\left[\begin{array}{l}
I_{y} \\
V_{x} \\
I_{z}
\end{array}\right]=\left[\begin{array}{ccc}
0 & 0 & 0 \\
\beta & 0 & 0 \\
0 & \pm \alpha & 0
\end{array}\right]\left[\begin{array}{c}
V_{y} \\
I_{x} \\
V_{z}
\end{array}\right] .
$$

Taking the non-ideal effects of CCII into consideration, the voltage transfer function of the circuit topology, which is given in Fig. 2, can be rearranged as given below

$$
\frac{V_{o}}{V_{i}}=\frac{\alpha_{1} \alpha_{2} \beta_{1} \beta_{2} Y_{1} Y_{3}}{Y_{2} Y_{4}}
$$

The equation that satisfies the condition of oscillation can be rearranged as

$$
\left[\frac{\alpha_{1} \alpha_{2} \beta_{1} \beta_{2} G_{1} G_{3}}{s^{2} C_{2} C_{4}+s\left(C_{2} G_{4}+C_{4} G_{2}\right)+G_{2} G_{4}}\right]\left[-\frac{\alpha_{3} \beta_{3}}{s C_{5} R_{5}}\right]=1 .
$$

Characteristic equation of the oscillator is modified to

$$
\begin{aligned}
& s^{3}+s^{2} \frac{\left(C_{2} G_{4}+C_{4} G_{2}\right)}{C_{2} C_{4}}+s \frac{G_{2} G_{4}}{C_{2} C_{4}}+ \\
& +\frac{\alpha_{1} \alpha_{2} \alpha_{3} \beta_{1} \beta_{2} \beta_{3} G_{1} G_{3} G_{5}}{C_{2} C_{4} C_{5}}=0 .
\end{aligned}
$$

Radian frequency is calculated as

$$
\omega_{0}=\frac{1}{\sqrt{R_{2} R_{4} C_{2} C_{4}}} .
$$

It can be seen from (24) that the current tracking error and voltage tracking error parameters do not affect the oscillation frequency.

Condition of oscillation can be rearranged as 


$$
G_{2} G_{4} C_{5}\left(C_{2} G_{4}+C_{4} G_{2}\right)=\alpha_{1} \alpha_{2} \alpha_{3} \beta_{1} \beta_{2} \beta_{3} G_{1} G_{3} G_{5} C_{2} C_{4}
$$

Equation (25) shows that in non-ideal case, the oscillation condition can still be controlled independently without interacting with the oscillation frequency and that the effects of $\alpha_{1}, \alpha_{2}, \alpha_{3}, \beta_{1}, \beta_{2}, \beta_{3}$ can be minimized by suitable preadjustment values of $R_{1}, R_{3}, R_{5}$, and $C_{5}$ components.

Taking the non-ideal effects of CCII into consideration, the current transfer function is calculated as

$$
\frac{I_{o 2}(s)}{I_{o 1}(s)}=\frac{\alpha_{1} \beta_{1}}{s R_{1} C_{5}} .
$$

And the voltage transfer function is calculated as

$$
\frac{V_{o 2}(s)}{V_{o 1}(s)}=\frac{s R_{5} C_{5}}{\alpha_{3} \beta_{3}} .
$$

Equations (26) and (27) show that the current tracking error and voltage tracking error parameters affect the gain, but not the phase difference between the quadrature current outputs and between the quadrature voltage outputs.

\section{Simulation Results}

Workability of the proposed filter and oscillator circuits is verified and performance analysis is carried out by PSPICE software using $0.18 \mu \mathrm{m}$ CMOS model parameters commercially available by MOSIS. In this work, the CMOS structure of MOCCII, which is given in Fig. 7, is used for all types of current conveyors employed in the circuit realizations. This circuit is derived from the DOCCII circuit introduced in [10] by adding an extra output stage to be used as the second $z+$ terminal in the oscillator circuit. MOSFET dimensions are modified as given in Table III and the supply voltage is applied as symmetrical $\pm 0.9 \mathrm{~V}$.

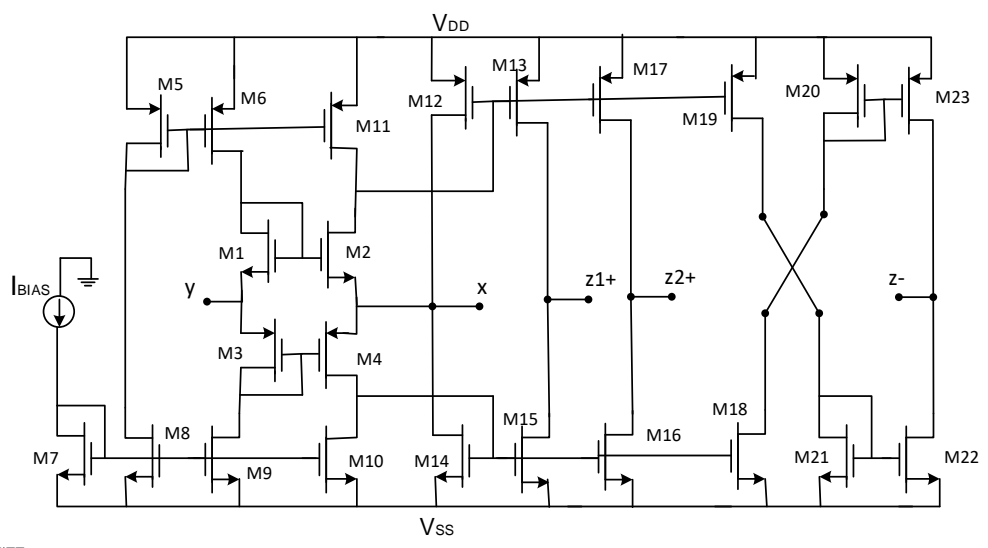

Fig. 7. CMOS structure of MOCCII.

TABLE III. MOSFET DIMENSIONS OF MOCCII.

\begin{tabular}{|c|c|c|}
\hline Transistor & $\mathbf{W}(\boldsymbol{\mu m})$ & $\mathbf{L}(\boldsymbol{\mu m})$ \\
\hline M1, M2 & 8.4 & 0.18 \\
\hline M3, M4 & 25.2 & 0.18 \\
\hline M5, M6, M11-M13, M17, M19, M20, M23 & 12.6 & 0.18 \\
\hline M7-M10, M14-M16, M18, M21, M22 & 4.2 & 0.18 \\
\hline
\end{tabular}

In the simulation, the passive component values of the filters are taken as given in Table IV.

TABLE IV. PASSIVE COMPONENT VALUES OF FILTERS.

\begin{tabular}{|c|c|c|c|}
\hline \multirow{2}{*}{ Component } & \multicolumn{3}{|c|}{ Filter Type } \\
\cline { 2 - 4 } & $\mathbf{L P}$ & $\mathbf{H P}$ & $\mathbf{B P}$ \\
\hline $\mathbf{R}_{\mathbf{1}}$ & $300 \Omega$ & - & $150 \Omega$ \\
\hline $\mathbf{R}_{\mathbf{2}}$ & $1 \mathrm{k} \Omega$ & $5 \mathrm{k} \Omega$ & $1 \mathrm{k} \Omega$ \\
\hline $\mathbf{R}_{\mathbf{3}}$ & $300 \Omega$ & - & - \\
\hline $\mathbf{R}_{\mathbf{4}}$ & $1 \mathrm{k} \Omega$ & $1 \mathrm{k} \Omega$ & $1 \mathrm{k} \Omega$ \\
\hline $\mathbf{C}_{1}$ & - & $20 \mathrm{pF}$ & - \\
\hline $\mathbf{C}_{\mathbf{2}}$ & $100 \mathrm{pF}$ & $20 \mathrm{pF}$ & $100 \mathrm{pF}$ \\
\hline $\mathbf{C}_{3}$ & - & $400 \mathrm{pF}$ & $25 \mathrm{pF}$ \\
\hline $\mathbf{C}_{4}$ & $100 \mathrm{pF}$ & $100 \mathrm{pF}$ & $100 \mathrm{pF}$ \\
\hline
\end{tabular}

MOSFET dimensions and gate voltages used for active resistor realization are taken as $W / L=1.26 \mu \mathrm{m} / 0.18 \mu \mathrm{m}$ for M1, M2, M5, and M6, $W / L=0.38 \mu \mathrm{m} / 0.18 \mu \mathrm{m}$ for $\mathrm{M} 3, \mathrm{M} 4, \mathrm{M} 7, \mathrm{M} 8$, and $V_{C 1}=V_{C 2}=V_{C 3}=V_{C 4}=0.9 \mathrm{~V}$ in LP filter, $W / L=0.38 \mu \mathrm{m} / 0.18 \mu \mathrm{m}$ for M3, M4, M7, M8, and $V_{C 2}=0.18 \mathrm{~V}, \quad V_{C 4}=0.9 \mathrm{~V}$ in $\mathrm{HP}$ filter, $W / L=$
$2.52 \mu \mathrm{m} / 0.18 \mu \mathrm{m}$ for M1 and M2, $W / L=0.38 \mu \mathrm{m} / 0.18 \mu \mathrm{m}$ for M3, M4, M7, M8, and $V_{C 1}=V_{C 2}=V_{C 4}=0.9 \mathrm{~V}$ in BP filter to obtain required resistor values.

Using the values of Table IV, the center frequency is calculated as $1.59 \mathrm{MHz}$, while in the simulation it is measured as $1.57 \mathrm{MHz}$ in LP filter, $1.55 \mathrm{MHz}$ in HP filter, and $1.58 \mathrm{MHz}$ in $\mathrm{BP}$ filter. Frequency domain responses of the filter are sketched in Fig. 8.

The quadrature oscillator is simulated by taking the component values which are given in Table V. MOSFET dimensions and gate voltages used for active resistor realization in the oscillator are taken as $W / L=$ $0.76 \mu \mathrm{m} / 0.18 \mu \mathrm{m}$ for all M1-M10, and $V_{C 1}=V_{C 2}=V_{C 3}=V_{C 4}=V_{C 5}=0.9 \mathrm{~V}$ to obtain the resistor value of $500 \Omega$. Using the values of Table $\mathrm{V}$, the oscillation frequency $\left(f_{o}\right)$ is calculated as $3.18 \mathrm{MHz}$ and in the simulation it is measured to be $3.24 \mathrm{MHz}$ with a deviation of $1.88 \%$. The bias currents ( $I_{\text {BIAS }}$ ) are adjusted to $50 \mu \mathrm{A}$ in the first two current conveyors and $30 \mu \mathrm{A}$ in the third current conveyor.

Quadrature oscillator is simulated for both voltage-mode and current-mode operations. Initial state and steady state waveforms of the voltage outputs and frequency spectrum of the oscillator are given in Fig. 9, Fig. 10, and Fig. 11, 
respectively. At the oscillation frequency of $3.24 \mathrm{MHz}$, the measured total harmonic distortion (THD) of the voltage output signals are $2.00 \%$ for $V_{o 1}$ when the amplitude is $357.33 \mathrm{mV}$ and $2.94 \%$ for $V_{o 2}$ when the amplitude is $178.38 \mathrm{mV}$.

Tuning of the oscillation frequency is examined by applying a variable control voltage $\left(V_{C}\right)$ to the gate of
MOSFETs (M1-M10) in the range from $0.6 \mathrm{~V}$ to $0.9 \mathrm{~V}$. The measured frequency values against this voltage range vary between $2.21 \mathrm{MHz}$ and $3.24 \mathrm{MHz}$, while in theoretical this variation is between $2.12 \mathrm{MHz}$ and $3.18 \mathrm{MHz}$. Figure 12 shows the variation of the oscillation frequency versus MOSFET gate voltage. Since the resistor values are chosen equal in the oscillator circuit, the frequency tuning can be easily done by a single control voltage.

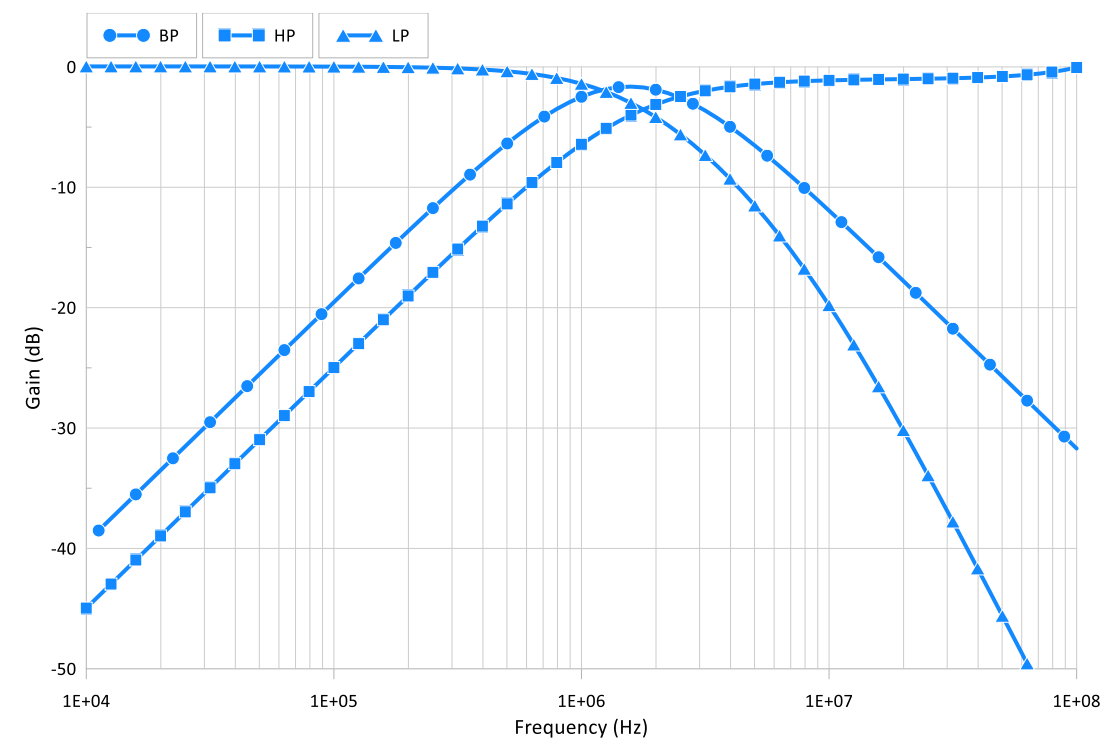

Fig. 8. Frequency domain responses of the proposed filter.

TABLE V. PASSIVE COMPONENT VALUES OF THE QUADRATURE OSCILLATOR.

\begin{tabular}{|c|c|c|c|c|c|c|c|}
\hline $\mathbf{R}_{1}$ & $\mathbf{R}_{2}$ & $\mathbf{R}_{\mathbf{3}}$ & $\mathbf{R}_{4}$ & $\mathbf{R}_{5}$ & $\mathrm{C}_{2}$ & $\mathrm{C}_{4}$ & $\mathrm{C}_{5}$ \\
\hline $500 \Omega$ & $500 \Omega$ & $500 \Omega$ & $500 \Omega$ & $500 \Omega$ & $100 \mathrm{pF}$ & $100 \mathrm{pF}$ & $50 \mathrm{pF}$ \\
\hline
\end{tabular}

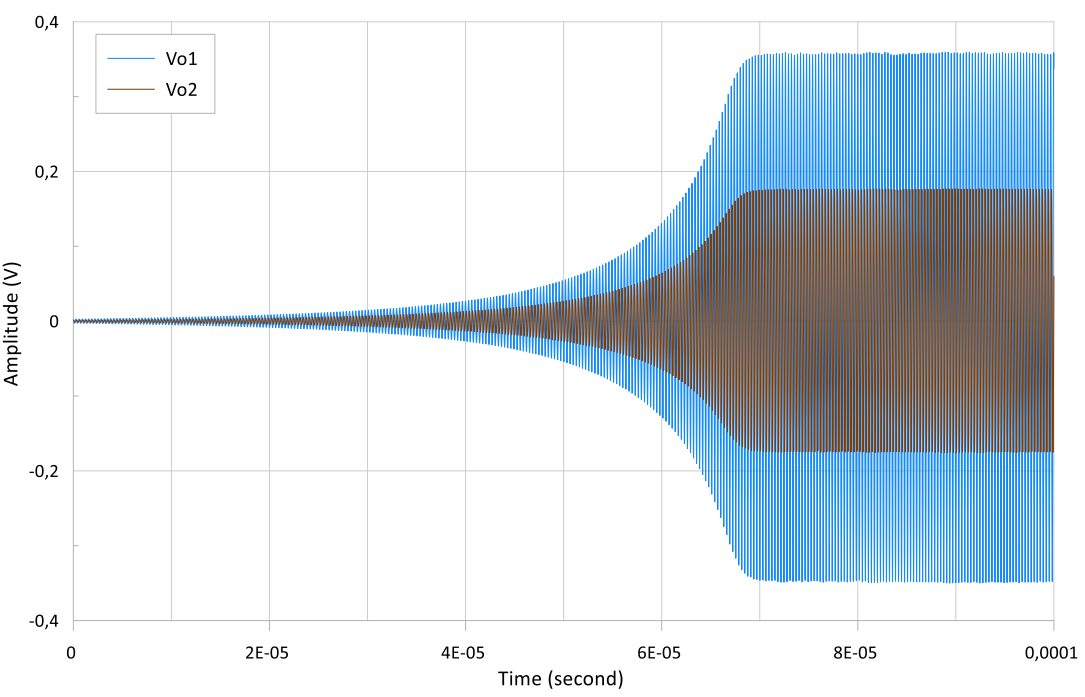

Fig. 9. Initial state waveform of voltage outputs.

Steady state waveforms of the quadrature current outputs are given in Fig. 13. Amplitudes of voltage outputs vary from $251.94 \mathrm{mV}$ to $357.33 \mathrm{mV}$ for $V_{o 1}$ and from $124.00 \mathrm{mV}$ to $178.38 \mathrm{mV}$ for $V_{o 2}$, likewise, the amplitudes of current outputs vary from $170.93 \mu \mathrm{A}$ to $282.30 \mu \mathrm{A}$ for $I_{o 1}$ and from $85.40 \mu \mathrm{A}$ to $141.06 \mu \mathrm{A}$ for $I_{o 2}$ while the frequency tuning is made by control voltage in the range of $0.6 \mathrm{~V}-$ $0.9 \mathrm{~V}$. These variation rates can be considered quite low when compared to similar electronically tuneable oscillator circuits. If equal amplitude quadrature outputs are needed, an additional automatic gain control (AGC) circuit can be used. The variation of output amplitudes versus oscillation frequency is sketched in Fig. 14 for voltage-mode and in Fig. 15 for current-mode operations. Figure 16 and Figure 17 show the simulated THD values of the output signals. As can be seen from these figures, as the frequency increases, the THD values decrease from $5 \%$ to $2.00 \%$ for $V_{o 1}$ and from $5 \%$ to $2.94 \%$ for $V_{o 2}$ at the frequency of $3.24 \mathrm{MHz}$. In current mode operations, THD values remain below $4 \%$, and at the frequency of $3.15 \mathrm{MHz}$, they reduce to $2.15 \%$ for 
$I_{o 1}$ and $1.82 \%$ for $I_{o 2}$. However, these values can be reduced by using AGC circuit.

Lissajous pattern, which indicates the relationship between the two quadrature voltage outputs of the oscillator, is given in Fig. 18. From this pattern, the measured phase error between the two output signals does not exceed $2.5 \%$ in the tested frequency range. Figure 19 shows the fluctuation of phase error percentage versus oscillation frequency.

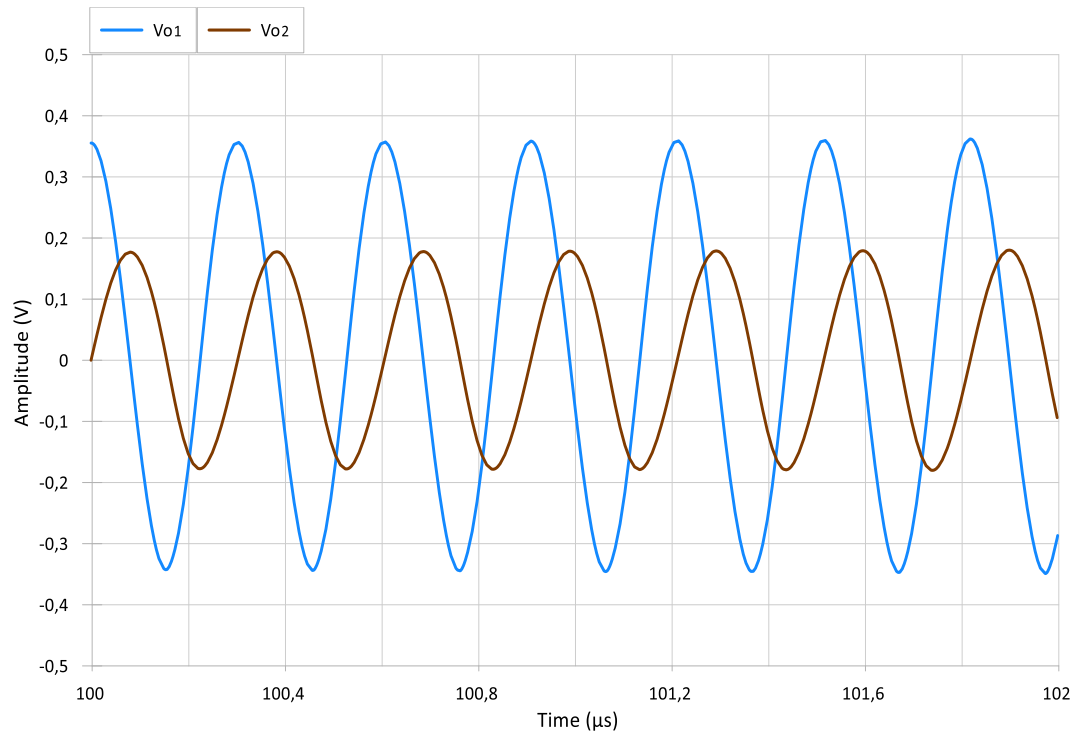

Fig. 10. Steady state waveform of voltage outputs at $3.24 \mathrm{MHz}$.

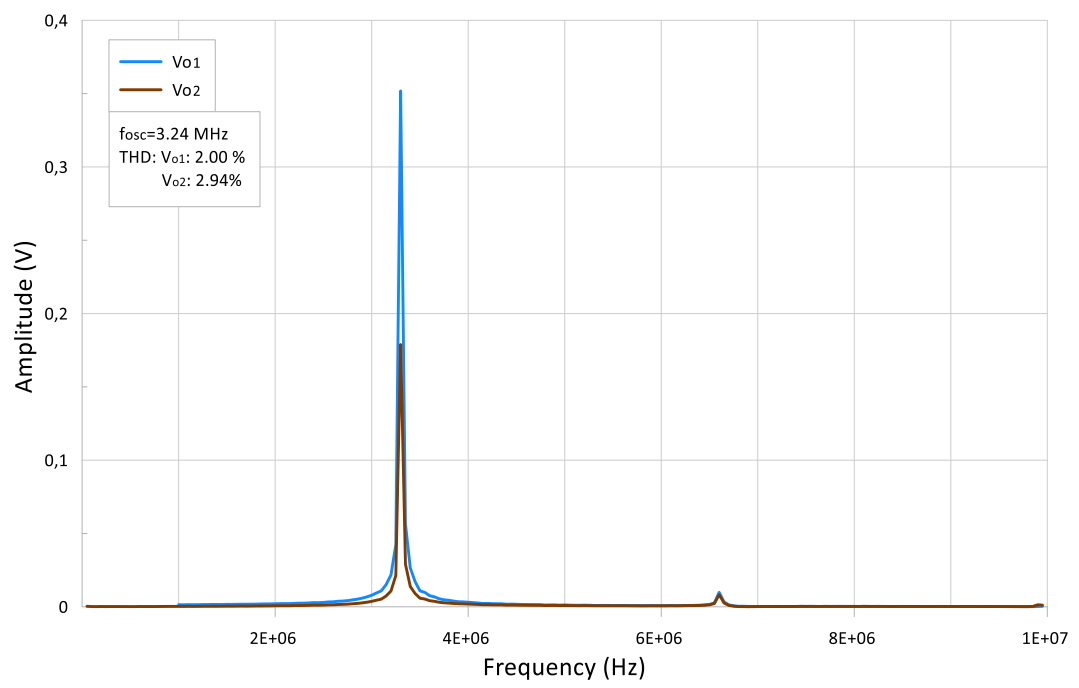

Fig. 11. Frequency spectrum.

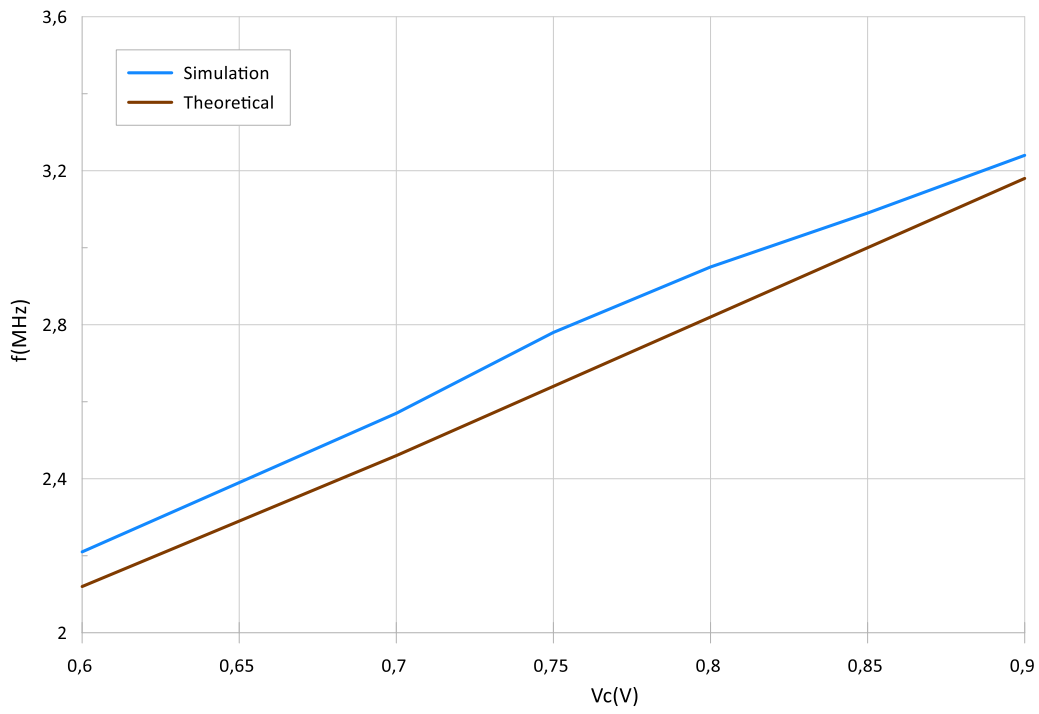

Fig. 12. Frequency tuning by MOSFET gate voltage. 


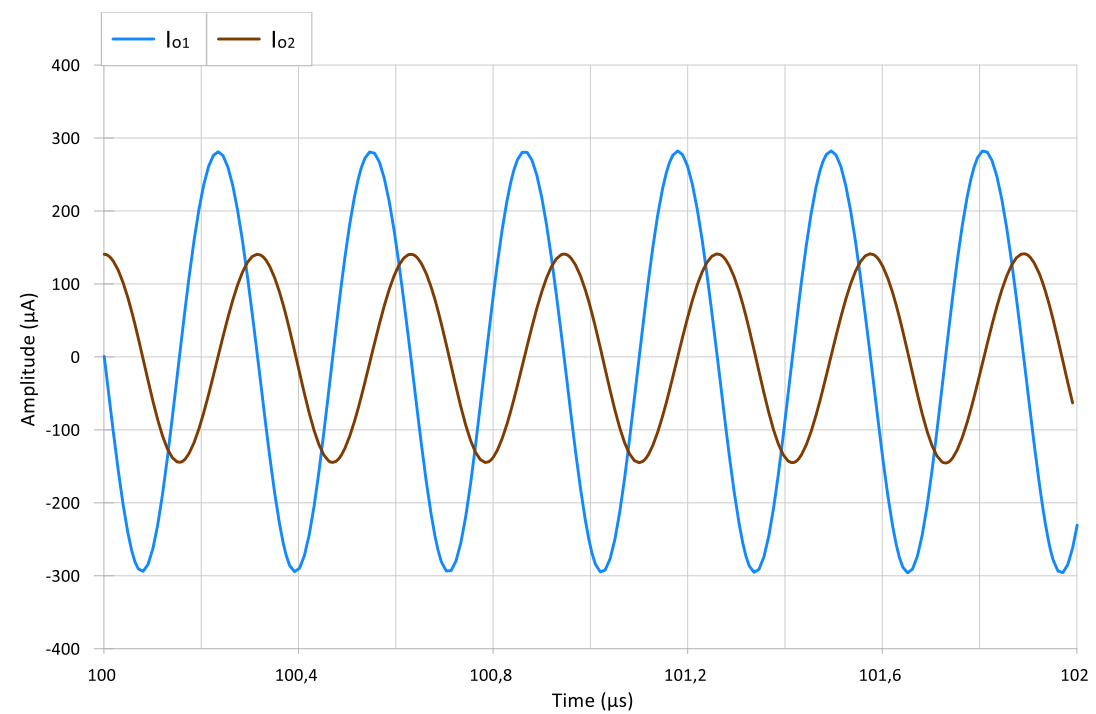

Fig. 13. Steady state waveform of current outputs at $3.15 \mathrm{MHz}$.

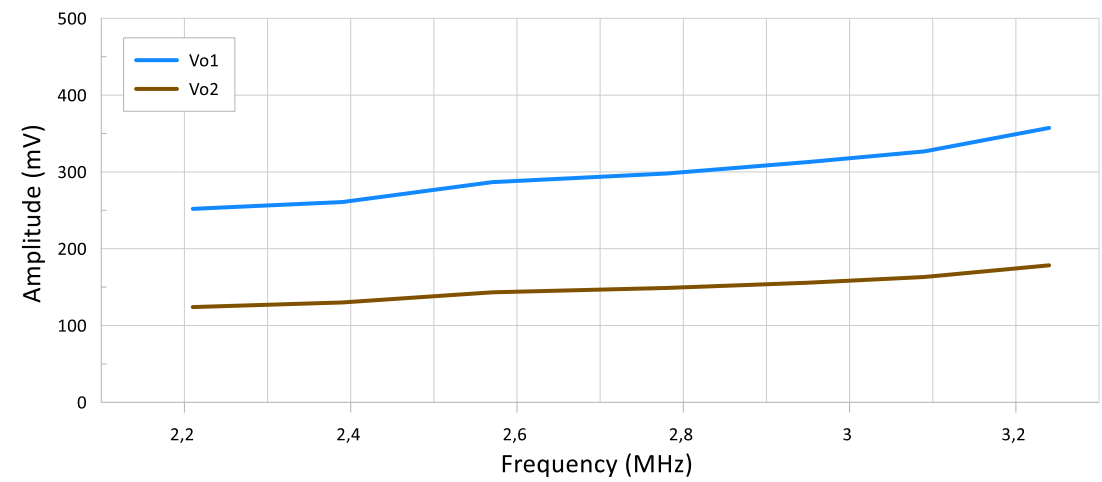

Fig. 14. Variation of voltage output amplitudes versus frequency.

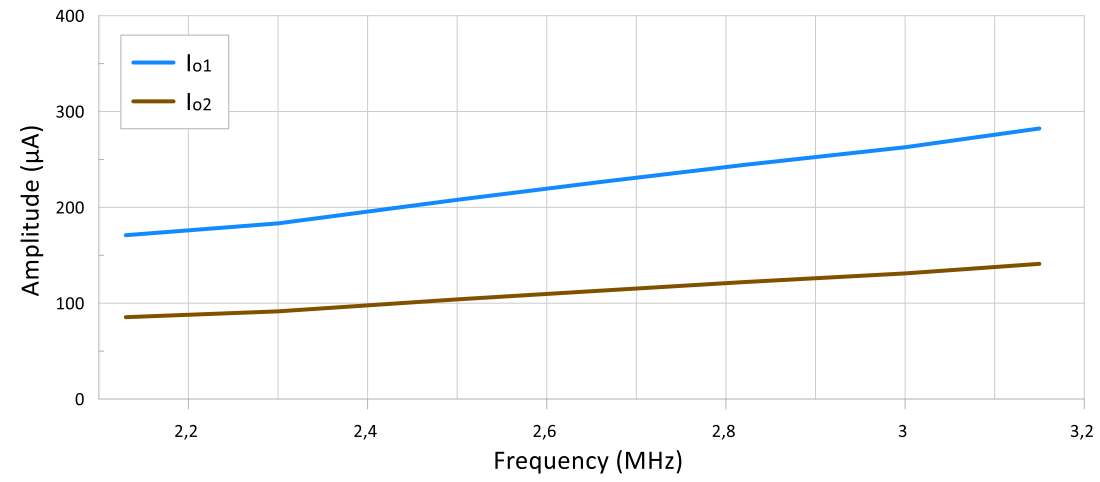

Fig. 15. Variation of current output amplitudes versus frequency.

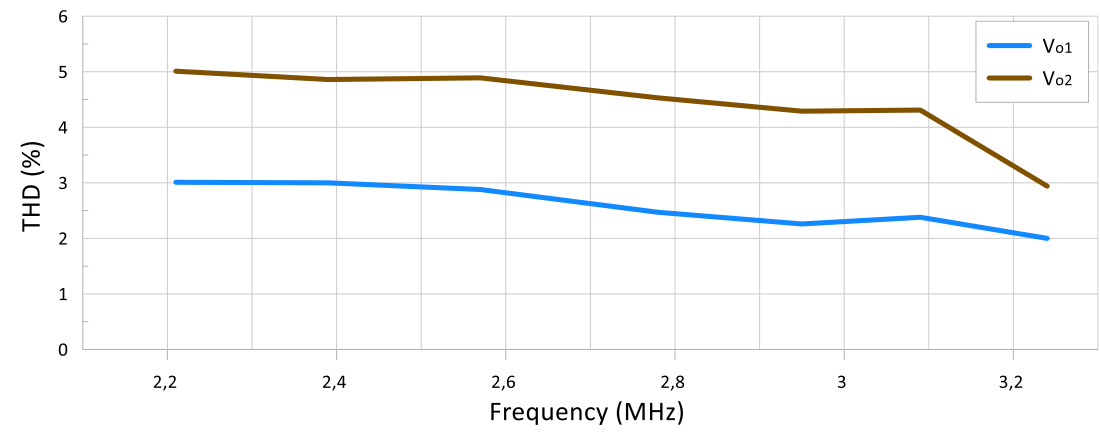

Fig. 16. THD graphic of voltage output amplitudes. 


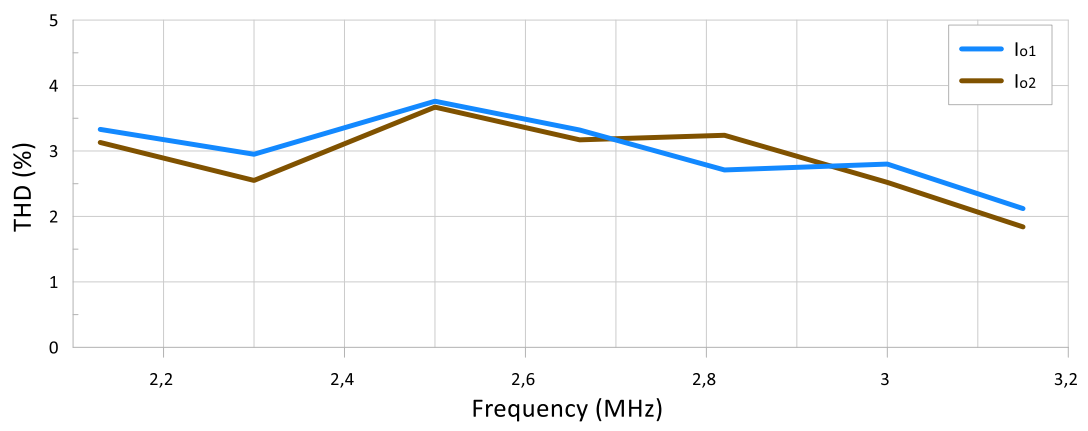

Fig. 17. THD graphic of current output amplitudes.

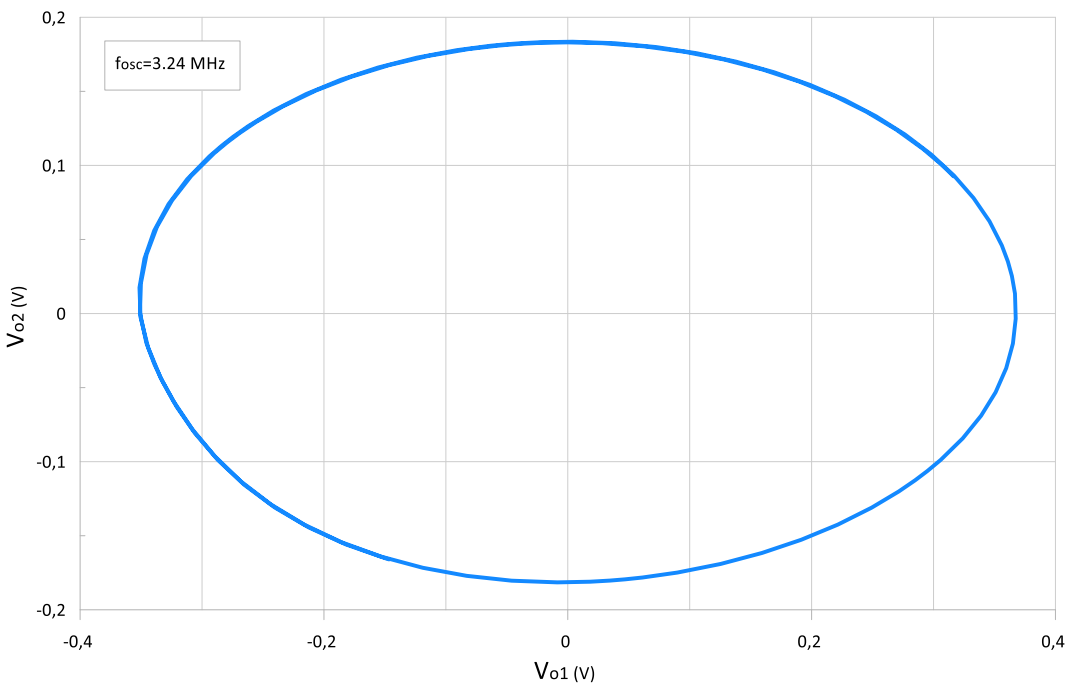

Fig. 18. Lissajous pattern.

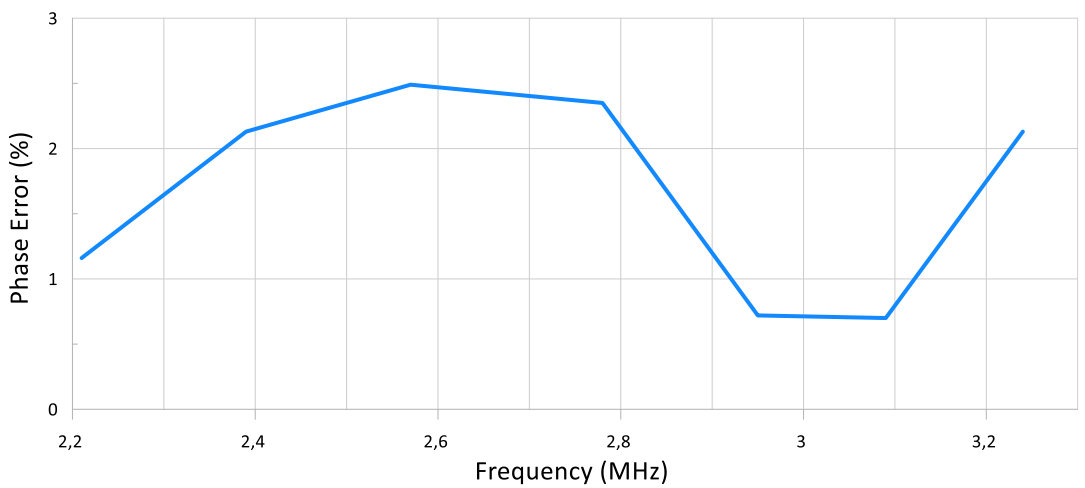

Fig. 19. Phase error versus oscillation frequency.

\section{CONCLUSIONS}

In this article, a new electronically tuneable MOS-C third order oscillator and a biquadratic filter, which are using all grounded passive components, have been presented. Voltage-mode second order LP, HP, and BP filters using CCIIs and current/voltage mode third order quadrature oscillator using MOCCIIs are synthesized from the proposed topology. PSPICE simulation has been done to evaluate the proposed circuits' performance and it is confirmed that the simulation and theoretical analysis results are in good consistency. Through MOS-C implementation and using all grounded components, the proposed filter and oscillator circuits are both compatible with integration. Passive component sensitivities are shown to be lesser than unity for both oscillator and filter circuits. Condition of oscillation and oscillation frequency can be electronically controlled independently. Electronic tuning of the oscillation frequency by MOSFET gate voltage is demonstrated for a tested frequency range in both voltagemode and current-mode operations. By taking the resistor values equal, the oscillation frequency can be easily tuned via a single control voltage. Taking into consideration the $0.18 \mu \mathrm{m}$ CMOS process parameter set, in the range from $0.6 \mathrm{~V}$ to $0.9 \mathrm{~V}$ of the control voltage, the oscillation frequency is precisely tuned between $2.21 \mathrm{MHz}$ and $3.24 \mathrm{MHz}$ in voltage-mode and between $2.13 \mathrm{MHz}$ and $3.15 \mathrm{MHz}$ in current-mode operations with quadrature phase error less than $2.5 \%$. In the tested frequency range, THD values remain below $5 \%$ for voltage outputs and below $4 \%$ for current outputs. It is measured that THD levels decrease to $2.00 \%$ for $V_{o 1}, 2.94 \%$ for $V_{o 2}, 2.15 \%$ for $I_{o 1}$, and $1.82 \%$ for $I_{o 2}$. However, these values can be significantly 
reduced by using AGC circuit by external means.

\section{CONFLICTS OF INTEREST}

The authors declare that they have no conflicts of interest.

\section{REFERENCES}

[1] R. Senani and D. R. Bhaskar, "Single op-amp sinusoidal oscillators suitable for generation of very low frequencies", IEEE Transactions on Instrumentation and Measurement, vol. 40, no. 4, pp. 777-779, 1991. DOI: $10.1109 / 19.85353$.

[2] R. Holzel, "Simple wide-band sine wave quadrature oscillator", IEEE Transactions on Instrumentation and Measurement, vol. 42, no. 3, pp. 758-760, 1993. DOI: 10.1109/19.231604.

[3] M. T. Ahmed, I. A. Khan, and N. Minhaj, "On transconductance-C quadrature oscillators", International Journal of Electronics, vol. 83, no. 2, pp. 201-208, 1997. DOI: 10.1080/002072197135526.

[4] D. R. Bhaskar and R. Senani, "New CFOA based single element controlled sinusoidal oscillators", IEEE Transactions on Instrumentation and Measurement, vol. 55, no. 6, pp. 2014-2021, 2006. DOI: 10.1109/TIM.2006.884139.

[5] S. S. Gupta and R. Senani, "Grounded-capacitor SRCOs using a single differential difference complementary current feedback amplifier", IEEE Proc. Circuits Devices Syst., vol. 152, no. 1, pp. 38 48, 2005. DOI: 10.1049/ip-cds:20040976.

[6] J.-W. Horng, C.-L. Hou, C.-M. Chang, W.-Y. Chung, H.-W. Tang, and Y.-H. Wen, "Quadrature oscillators using CCIIs", International Journal of Electronics, vol. 92, no. 1, pp. 21-31, 2005. DOI: 10.1080/00207210412331332899.

[7] S. B. Salem, A. B. Saied, D. S. Masmoudi, and M. Loulou, "A new CMOS current controlled oscillator with minimum phase noise based on a low parasitic resistance CCII", WSEAS Transactions on Circuits and Systems, vol. 10, no. 9, pp. 289-298, 2011.

[8] J. Mohan, B. Chaturverdi, and S. Maheshwari, "Low voltage mixedmode multi phase oscillator using single FDCCII", Electronics, vol. 20, no. 1, pp. 36-42, 2016. DOI: 10.7251/ELS1620036M.

[9] S. S. Gupta and R. Senani, "Realization of current mode SRCOs using all grounded passive elements", Frequenz, vol. 57, pp. 26-37, 2003. DOI: 10.1515/FREQ.2003.57.1-2.25.

[10] N. Minhaj, "Dual-output second generation current conveyor based voltage-mode sinusoidal oscillator modified for chaos generators", International Journal of Recent Trends in Engineering, vol. 2, no. 5, pp. 315-318, 2009. DOI: 10.1109/ARTCom.2009.241.

[11] P. Gupta, P. K. Jain, D. S. Ajnar, and R. K. Sahu, "Design of sinusoidal oscillator using second generation current conveyor", Paripex Indian Journal of Research, vol. 2, no. 3, pp. 129-131, 2013. DOI: 10.36106/paripex.

[12] G. Sharma, J. Kaur, and N. Gupta, "Current conveyor based sinusoidal oscillator with its application", International Journal of Science and Research (IJSR)", vol. 3, no. 5, pp. 1897-1900, 2014.

[13] H. Ciçekli and A. Gökçen, "Composite second generation current conveyor based tunable MOS-C quadrature sinusoidal oscillator design and comparative performance analysis", WSEAS Transactions on Circuits and Systems, vol. 14, pp. 488-493, 2015.

[14] R. Sotner, J. Jerabek, N. Herencsar, J.-W. Horng, K. Vrba, and T. Dostal, "Simple oscillator with enlarged tunability range based on ECCII and VGA utilizing commercially available analog multiplier", Measurement Science Review, vol. 16, no. 2, pp. 35-41, 2016. DOI: 10.1515/msr-2016-0006.

[15] W. Tangsrirat and S. Pisitchalermpong, "CDBA-based quadrature sinusoidal oscillator”, Frequenz, vol. 61, pp. 102-104, 2007. DOI: 10.1515/FREQ.2007.61.3-4.102.

[16] A. Ü. Keskin, C. Aydin, E. Hancioglu, and C. Acar, "Quadrature oscillator using current differencing buffered amplifiers", Frequenz, vol. 60, pp. 57-60, 2006. DOI: 10.1515/FREQ.2006.60.3-4.57.

[17] S. Pisitchalermpong, D. Prasertsom, T. Piyatat, W. Tangsrirat, and W. Surakampontorn, "Current tunable quadrature oscillator using only CCCDBAs and grounded capacitors", in Proc. of Int. Conference on Elect. Engineering, Electronics, Computer, Telecommunications and Information Technology, Thailand, 2007, pp. 32-35.

[18] A. Lahiri, "Low-frequency quadrature sinusoidal oscillators using current differencing buffered amplifiers", Indian Journal of Pure \& Applied Physics, vol. 49, pp. 423-428, 2011.

[19] A. Ü. Keskin and D. Biolek, "Current mode quadrature oscillator using current differencing transconductance amplifiers (CDTA)", IEEE Proc. Circuits, Devices and Systems, vol. 153, pp. 214-218, 2006. DOI: $10.1049 /$ ip-cds:20050304.
[20] D. Biolek, V. Biolkova, and A.Ü. Keskin, "Current mode quadrature oscillator using two CDTAs and two grounded capacitors", in Proc. of 5th WSEAS Int. Conference on System Science and Simulation in Engineering, Spain, 2006, pp. 368-370.

[21] R. Keawon and W. Jaikla, "A resistor-less current-mode quadrature sinusoidal oscillator employing single CCCDTA and grounded capacitors", Przeglad Electrotechniczny (Electrical Review), vol. 87, no. 8, pp. 138-141, 2011.

[22] S.-I. Liu and Y.-H. Liao "Current mode quadrature sinusoidal oscillator using single FTFN", International Journal of Electronics", vol. 81, no. 2, pp. 171-175, 1996. DOI: 10.1080/002072196136832.

[23] S. Avireni and C. S. Pittala, "Grounded resistance/capacitancecontrolled sinusoidal oscillators using operational transresistance amplifier", WSEAS Transactions on Circuits and Systems, vol. 13, pp 145-152, 2014.

[24] R. Sotner, J. Jerabek, N. Herencsar, and K. Vrba, "Design of the simple oscillator with linear tuning and pi/4 phase shift based on emulator of the modified current differencing unit", IEICE Electronics Express, vol. 12, no. 19, pp. 1-7, 2015. DOI 10.1587/elex.12.20150557.

[25] N. Herencsar, J. Koton, K. Vrba, and I. Lattenberg, "New voltagemode universal filter and sinusoidal oscillator using only single DBTA”, International Journal of Electronics, vol. 97, no. 4, pp. 365 379, 2010. DOI: 10.1080/00207210903325229.

[26] R. Sotner, N. Herencsar, J. Jerabek, J. Koton, T. Dostal, and K. Vrba, "Electronically controlled oscillator with linear frequency adjusting for four-phase or differential quadrature output signal generation", International Journal of Circuit Theory and Applications, vol. 42, no. 12, pp. 1264-1289, 2014. DOI: 10.1002/cta.1919.

[27] T. Hajder, "Higher order loops improve phase noise of feedback oscillators", Applied Microwave \& Wireless, pp. 24-31, 2002.

[28] R. Pandey, N. Pandey, G. Komanapalli, and R. Anurag, "OTRA based voltage mode third order quadrature oscillator", International Scholarly Research Notices, vol. 2014, art. ID 126471, 2014. DOI: $10.1155 / 2014 / 126471$.

[29] H.-C. Chien, "Third-order sinusoidal oscillator using a single CMOS operational transresistance amplifier", Journal of Applied Science and Engineering, vol. 19, no. 2, pp. 187-196, 2016. DOI: 10.6180/jase.2016.19.2.09.

[30] J.-W. Horng, H. Lee, and J.-Y. Wu, "Electronically tunable thirdorder quadrature oscillator using CDTAs", Radioengineering, vol. 19, no. 2, pp. 326-330, 2010.

[31] J.-W. Horng, "Current/voltage-mode third order quadrature oscillator employing two multiple outputs CCIIs and grounded capacitors", Indian Journal of Pure \& Applied Physics, vol. 49, pp. 494-498, 2011.

[32] R. Pandey, N. Pandey, and S. K. Paul, "MOS-C third order quadrature oscillator using OTRA", in Proc. of 3rd International Conference on Computer and Communication Technology, India, 2012, pp. 77-80. DOI: 10.1109/ICCCT.2012.24.

[33] B. Chaturvedi and S. Maheshwari, "Third-order quadrature oscillator circuit with current and voltage outputs", International Scholarly Research Notices, vol. 2013, art. ID 385062, 2013. DOI: $10.1155 / 2013 / 385062$.

[34] B. C. Nagar and S. K. Paul, "Voltage mode third order quadrature oscillators using OTRAs", Analog Integrated Circuits and Signal Processing, vol. 88, pp. 517-530, 2016. DOI: 10.1007/s10470-0160781-6.

[35] R. Sotner, J. Jerabek, N. Herencsar, J. Petrzela, K. Vrba, and Z. Kincl, "Tunable oscillator derived from Colpitts structure with simply controllable condition of oscillation and synthetic inductor based on current amplifier and voltage differencing transconductance amplifier", in Proc. of 8th International Conference on Electrical and Electronics Engineering (ELECO), Bursa, Turkey, 2013, pp. 21-25. DOI: 10.1109/ELECO.2013.6713928.

[36] A. Kwawsibsam, B. Sreewirote, and W. Jaikla, "Third-order voltagemode quadrature oscillator using DDCC and OTAs", in Proc. of 2011 International Conference on Circuits, System and Simulation, 2011 vol. 7, pp. 317-321.

[37] I. Karacan and A. Gökçen, "A novel third order quadrature oscillator", The Eurasia Proceedings of Science, Technology, Engineering \& Mathematics (EPSTEM), vol. 4, pp. 67-73, 2018.

[38] G. Komanapalli, N. Pandey, and R. Pandey, "New realization of third order sinusoidal oscillator using single OTRA", AEU - International Journal of Electronics and Communications, vol. 93, pp. 182-190, 2018. DOI: 10.1016/j.aeue.2018.06.005.

[39] H.-P. Chen, Y.-S. Hwang, and Y.-T. Ku, "A new resistorless and electronic tunable third-order quadrature oscillator with current and 
voltage outputs", IETE Technical Review, vol. 35, no. 4, pp. 426-438, 2018. DOI: $10.1080 / 02564602.2017 .1324329$.

[40] J. Mohan, B. Chaturvedi, A. Kumar, and Jitender, "Active-C realization of multifunction biquadratic filter and third-order oscillator", Radio Science, vol. 55, pp. 1-9, 2020. DOI: 10.1029/2019rs006877.

[41] E. Wareechol, B. Knobnob, and M. Kumngern, "FDCCII-based thirdorder quadrature sinusoidal oscillator", in Proc. of 41st Int Conference on Telecommunications and Signal Processing, Athens, 2018, pp. 1-4. DOI: 10.1109/TSP.2018.8441208

[42] K. Khaw-Ngam, M. Kumngern, and F. Khateb, "Mixed-mode thirdorder quadrature oscillator based on single MCCFTA", Radioengineering, vol. 26, no. 2, pp. 522-535, 2017. DOI: 10.13164/re.2017.0522.

[43] J. Koton, N. Herencsar, K. Vrba, and B. Metin, "Current and voltagemode third-order quadrature oscillator", in Proc. of 13th International
Conference on Optimization of Electrical and Electronic Equipment (OPTIM 2012), Brasov, 2012, pp. 1203-1206. DOI: 10.1109/OPTIM.2012.6231795

[44] M. Kumngern and I. Kansiri, "Single-element control third-order quadrature oscillator using OTRAs", in Proc. of Twelfth International Conference on ICT and Knowledge Engineering, Bangkok, 2014, pp. 24-27. DOI: 10.1109/ICTKE.2014.7001529.

[45] M. T. Abuelma'atti and A. A.-A. Al-Ghumaiz, "Novel CCI-based single-element-controlled oscillators employing grounded resistors and capacitors", IEEE Transactions on Circuits and Systems I (Fundamental Theory and Applications), vol. 43, no. 2, pp. 153-155, 1996. DOI: $10.1109 / 81.486437$.

[46] M. T. Darkani and B. B. Bhattacharyya, "Generation and design of canonic grounded-capacitor variable-frequency RC-active oscillators", IEE Proc. G (Electronic Circuits and Systems), vol. 132, no. 4, pp. 153-160, 1985. DOI: 10.1049/ip-g-1.1985.0033.

This article is an open access article distributed under the terms and conditions of the Creative Commons Attribution 4.0 (CC BY 4.0) license (http://creativecommons.org/licenses/by/4.0/). 